\title{
Issues of Visual Search Methods in Digital Repositories
} \author{
Hassan-Montero ${ }^{3}$ \\ ${ }^{1}$ Universidad Distrital Francisco José de Caldas, Bogotá (Colombia) \\ ${ }^{2}$ Fundación Universitaria San Mateo, Bogotá (Colombia) \\ ${ }^{3}$ Universidad Internacional de la Rioja, Madrid (Spain)
}

Paulo Gaona-García ${ }^{1 *}$, Carlos Montenegro-Marín ${ }^{1}$, Elvis Gaona-García ${ }^{1}$, Adriana Gómez-Acosta ${ }^{2}$, Yusef

Received 22 March 2018 | Accepted 23 October 2018 | Published 26 October 2018

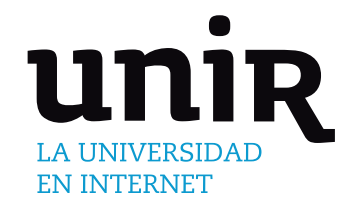

KEYWORDS

Search Interfaces, Metadata, Digital Repositories, Taxonomies, Information Visualization.

\section{INTRODUCTION}

C URRENTLY, the treatment of information poses major challenges not only because of the amount of information which needs to be handled but also because of the variety of formats in which it is presented. In this sense, recent studies conducted on the design and implementation of digital repositories indicate that a large majority include knowledge classification schemes [1], based on instruments such as ontologies and thesauri. The inclusion of these instruments allows experts to perform management and organization activities of thousands of digital resources. However, for their design and implementation with the aim of using them in a learning process, there are several considerations that should be taken into account and which are associated with: i) redundant information [2], ii) terminological use [3], iii) use of knowledge representation schemes [4,5], and iv) lack of understanding shown by users to know how to use the representation scheme $[6,7]$.

To some extent, the difficulties faced by some knowledge representation schemes are factors which may limit their inclusion in the development of search interfaces in digital repositories. However, information visualization plays an important role in facilitating the use of such classification instruments [8]. Currently, information visualization is considered as one of the fastest growing strategies given in various knowledge areas in recent years. This is reflected in the communicability it offers to understand complex information

* Corresponding author.

E-mail address: pagaonag@udistrital.edu.co that usually occurs without a classification and without any specific format. Therefore, on the front of design and development of digital repositories, they are presented as alternatives for gaining access to a collection of digital resources. Such initiatives have favoured the use of these tools and at the same time have become one of the most widely accepted alternatives to perform search processes on digital resources. However, the high consumption of resources which are necessary for their analysis, design and implementation to carry out their application in these types of fields make them to be undervalued.

The following article aims to present a number of factors and considerations for the development of search methods based on open digital repositories SKOS. Currently, within processes of search and navigation resources, the use of SKOS is very limited. However, there are several factors which can be carried out so as to give access to learning objects on the basis of knowledge areas. In order to do this, the following article is divided as follows: Section II provides a brief description of some of the most relevant visualization techniques. Subsequently, section III identifies the benefits, implications and limitations encountered in the use of visualization information. Section IV presents the study methodology. Section V shows an analysis of variables and evaluation criteria associated with visualization techniques, knowledge representation schemes and digital repositories to facilitate both the classification and visualization of specific themes. Finally, results of a case study are presented, applying these solutions to highlight critical success factors that these strategies offer to facilitate access to a collection of digital resources in repositories. 


\section{Theoretical FrameWork AND Related Studies}

In this section, the importance of information in search processes and access to digital resources is stressed. To do this, the importance of visualization of information on the development of search interfaces is first presented, followed by studies related to assessment criteria and associated with the area of usability studies. Finally, the first works on visualization information related to the field of digital repositories are mentioned.

\section{A. Works Associated with Digital Repositories}

In order to facilitate management and administration processes, learning objects are grouped and stored in digital repositories. Within these repositories, two types can be identified: i) Repositories containing learning objects and their metadata [9] -learning objects and their descriptors are within the same system [10]-, and ii) Repositories containing only metadata [11] -they contain only descriptors and the access to the object is made through a reference to its physical location found in another system or object repository.

Considering the aforementioned, a search for learning objects in any of these repositories could provide a long list of results. Therefore, if indicators to evaluate the quality of recorded information are not defined, the search process of learning objects may be an activity which requires a great deal of wasted time and effort by the user [12].

The use of digital repositories is centred on performing storagerelated educational materials in order to optimize their administration, management and search processes. However, the large volume of digital resources has generated a number of limitations, specifically those related to the use of repositories for gaining access to relevant instructional materials [8]. Such deficiencies have favoured the development and use of different alternatives associated with the implementation of enriched languages and knowledge representation schemes to execute classification activities, categorization and content management. The implementation of these strategies has generated the combination of a solid technological structure which is linked to a series of strategies of semantic enrichment from the use of knowledge representation schemes. To some extent, these solutions facilitate administration and management activities created by developers and repository creators [13]. However, for a conventional user (student and / or teachers), the use of such educational repositories is not an easy task, since they lack access strategies and mechanisms of conventional searches (textual, Boolean) working from the use of their interfaces [14]. This is a key factor which may make the learning process difficult, and therefore may generate a progressive abandonment of such tools.

\section{B. Works Associated with Search Interfaces}

In addition to language and knowledge representation schemes, repositories also provide alternative access to perform a search process by using visual interfaces, although some of these do not have them to facilitate such processes. Moreover, previous research has found that some search interfaces do not conform to the users' needs altogether [15]. Oftentimes, results displayed are not relevant according to search criteria defined by users [16]. Navigation problems have been identified when users want to check previously viewed records [17]. Authors like [18] found a series of problems related to interface design of an institutional repository in Korea. The study showed that subjects of interest were not sufficiently visible because navigation menus were too small and dark.

Other studies have revealed limitations to combine navigation strategies and search methods [19], in which interfaces do not allow to display (at first glance) the deployment of available materials in a repository from a specific knowledge area [20,21]. Such limitation is an influential factor for a user to continue using these tools, since it is difficult to determine whether it is worth continuing the process of exploring materials in the repository or whether it is better to rely on other external search strategies.

\section{Works Associated with Search Processes}

With regard to search activities, some results of related studies on the basis of usability criteria are highlighted. Authors like [18] found a number of limitations associated with the use of search interfaces and deployment strategies of digital resources. The authors propose a list of suggestions and recommendations related to the improvement in the definition of criteria and the distribution of results on the screen. Finally, some of the results obtained from recent studies associated with the use of interfaces in academic repositories are mentioned. For example, in [22] authors identified deficiencies in the user interfaces related to utility, learning and knowledge of the classification scheme. In [8] authors claim that poor definition of a knowledge representation scheme, specifically associated with taxonomies and keyphrases [23], is one of the factors which hinders the process of finding digital resources using interfaces based on visualization techniques. In addition to this, there are also some other factors which impede navigation on knowledge representation structures for locating digital resources. In terms of efficiency, results of these studies show that, under certain conditions, search interfaces lead to an under-utilisation of information, in cases where results of search processes of digital resources associated with other subjects or knowledge areas are not relevant. Such results may often be related to a poor definition of metadata, thus losing all semantic ability to make enriched searches based on themes or some specific knowledge area [22, 24].

\section{Methodology AND ApPlied Model fOR ANALYsis}

Considering these results, it is therefore necessary to design a work scheme outlining a series of activities linked to the identification of evaluation criteria for the analysis of search interfaces based on visualization techniques. Fig. 1 summarizes the work path which led to the development of this study.

In order to do this, the evaluation was performed throw a questionnaire, and made by five developers in the use of visualization tools. The purpose of the questionnaire was to identify qualitative aspects for the development of visual search interfaces based on 3 aspects: i) technical aspects of each library, ii) aspects of data integration of each library and finally, iii) visual aspects of each library. For the technical aspects, elements related to the characteristics of each library were considered such as ease of use, flexibility, scalability, performance, among others. Regarding data integration, its operation was considered from a predefined dataset for its deployment in each library, learning curve for data integration, navigation, hierarchical structure. Finally, some visual aspects associated with aesthetics, ease of navigation, among others, were considered.

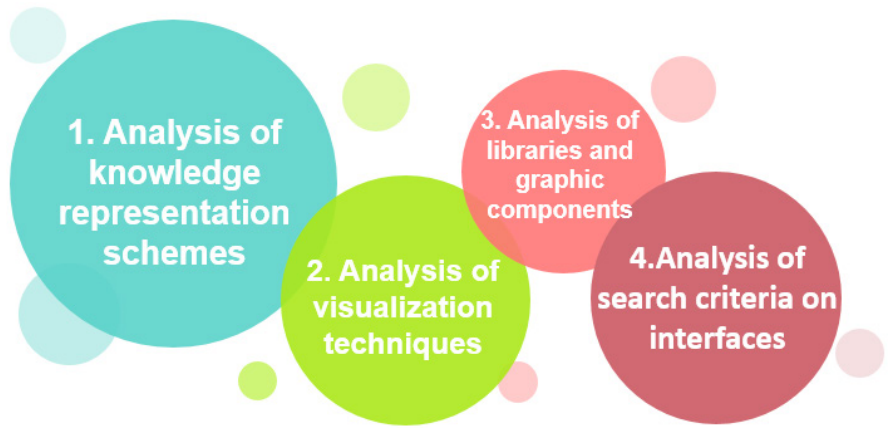

Fig. 1. Work scheme source: proprietary development. 
Such phases were considered with the aim to define a navigation map for the selection of criteria and factors which may have a significant influence on the development of visualization strategies applied to search interfaces in digital repositories. Considering this, each activity is presented below, as well as the assessment results shown in section IV and the definition of implications in section $\mathrm{V}$ respectively. In consequence the methodology is described as: 1) Analysis of knowledge representation schemes: At this stage, instruments associated with the most common knowledge representation schemes applied to digital repositories are identified. In addition to this, evaluation criteria for subsequent selection are defined. 2) Analysis of visualization techniques: For this phase, it is essential to define visualization techniques that facilitate exploration based on a knowledge representation scheme within a digital repository. Similarly, a study to determine the associated criteria for the selection of visualization techniques is conducted. 3) Analysis of libraries and graphical components: At this stage, the analysis of libraries and graphical components is carried out in order to select those that are most effective and which can lead towards the development of search interfaces based on visualization techniques, and finally 4) Analysis of search criteria on interfaces: A selection of factors associated with the design of search interfaces from the point of view of usability is made. Besides this, the principles related to the area of Human-Computer Interaction (HCI) are established.

\section{Results of Evaluation CRiteria}

This section presents an analysis of the factors which have a direct influence on the development of search interfaces based on visualization techniques. A number of analyses based on a study [25, 26] are made in order to identify selection criteria.

\section{A. Analysis of Knowledge Representation Scheme}

In the field of digital repositories, a knowledge representation scheme is defined as the different ways in which data can be structured and represented. This is done with the aim to facilitate classification processes, organization and association of concepts, based on a domain knowledge or a previously defined subject area.

Each knowledge representation technique requires a notation, which determines aspects of the subject area, levels of relationships, links and forms of association, among others. A knowledge representation scheme should be consistent and realistic to represent a subject area and its relationships in order to be effective in a learning environment [27]. This may either increase or decrease the user knowledge, among other things. Authors like [28], classifies these knowledge organization strategies in five different principles: 1) Elimination of ambiguities, related to the way a representation scheme facilitates the location of a term or concept without duplicating it. 2) Synonym control, referring to the monitoring performed by the structure to distinguish and / or associate multiple terms conceptually related. 3) Hierarchical relationships, which are related to the structure ability to determine the relationship level of two terms according to their meaning. 4) Associative relationships, which mean the structure ability to indicate the relationship of terms coming together to represent concepts associated with ideas. 5) Presentation of properties related to the knowledge representation instrument and its ability to associate levels of semantic representation from the use of metadata.

Considering the differences and features of the knowledge representation schemes analysed by [29], as well as the approaches raised by [28] on knowledge representation schemes, Table I shows some of the most representative features provided by each of these knowledge representation schemes and which are focused on the development of digital repositories.
TABLE I. FeAtures Of Knowledge Representation Instruments

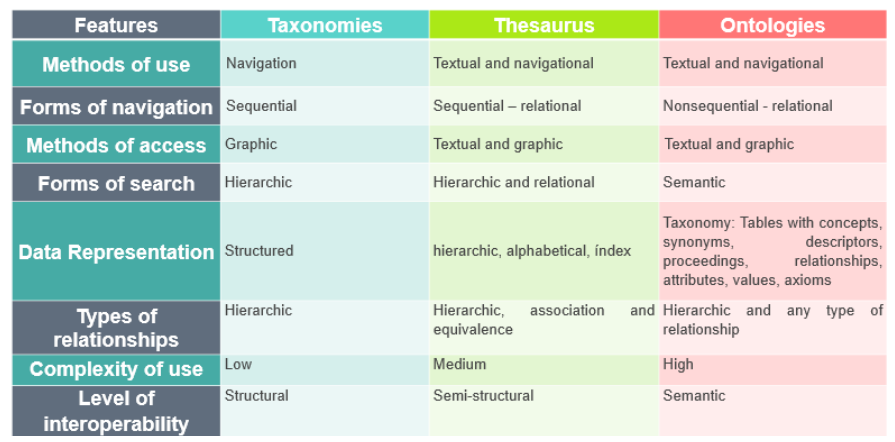

According to previous studies made by $[30,8]$, in the design of digital repositories, the most common instruments used to represent knowledge are: taxonomies, ontologies, thesauri, graphs, mind maps, among others.

Fig. 2 shows a study of the first three instruments, as they are the most common knowledge representation schemes for the design of digital repositories. The vertical axis shows the factors which have been defined for executing the verification process in three different instruments of knowledge representation. The first five factors are related to management criteria and information classification, selected from studies made by [24]. The following three factors are associated with usability criteria, whereas the last two make emphasis on search criteria and ease of implementation within a digital repository.

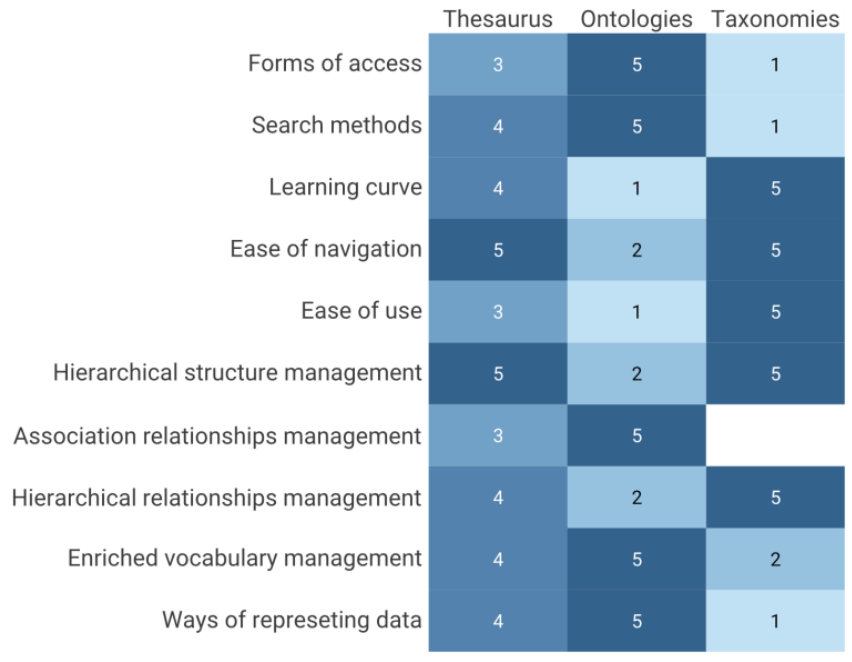

Fig. 2. Evaluation criteria for selection of knowledge representation scheme.

\section{B. Analysis of Visualization Techniques}

Fig. 3 shows summarised results of an evaluation administered for the selection of visualization techniques to facilitate the development of interface processes of visual search on digital repositories. The evaluation process executed at each interface was performed according to usability results obtained during the studies and the experience gained in the implementation and development of two projects: Organic.Edunet [31], and VOA3R/AGRIS [32].

From the assessment made in Fig. 3 by developers using the questionnaire defined, and according to evaluation criteria identified, the following interfaces can be identified as the most appropriate for implementation:

1. Specific features of each visualization technique: The interfaces which had better valuation according to aesthetic properties and classification methods of each of the hierarchies defined in a knowledge representation scheme were tree and radial. 


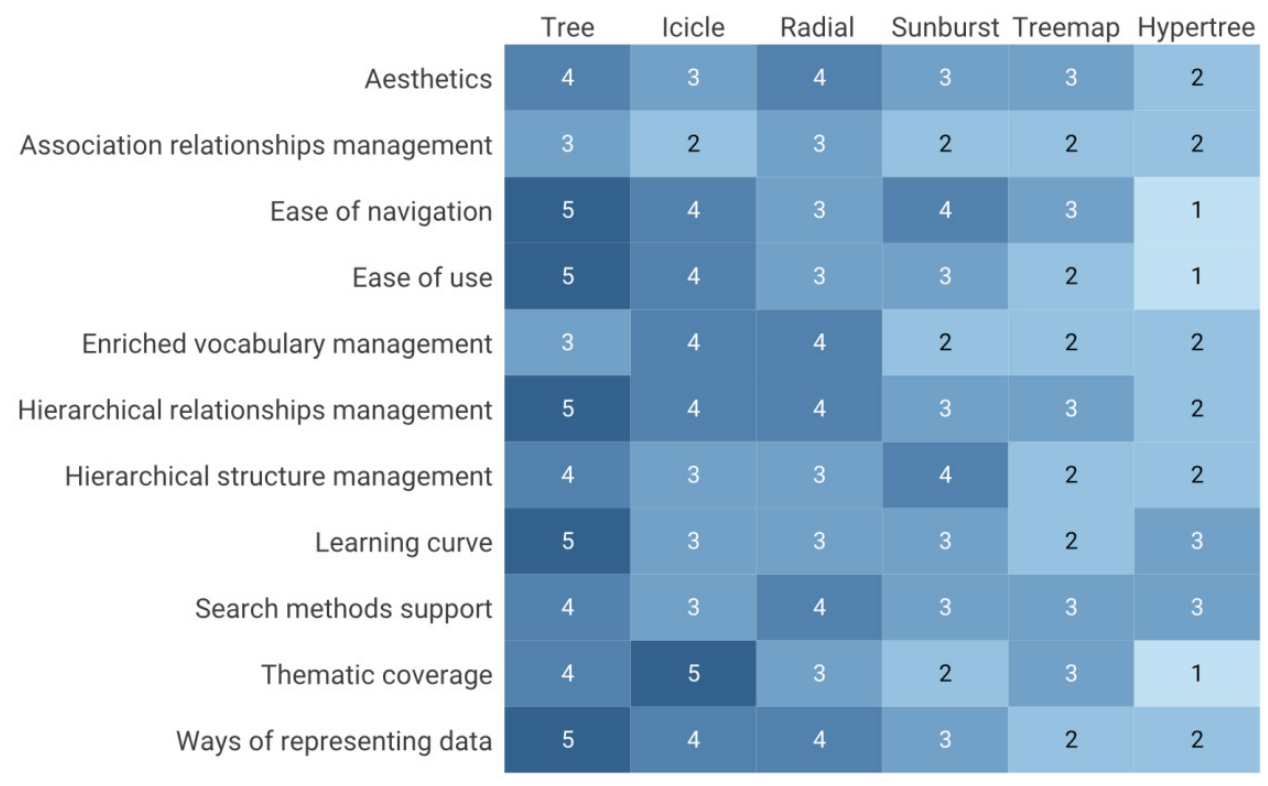

Fig. 3. Evaluation criteria for the selection of visualization techniques.

2. Development Features: In this category, the tree interfaces icicle and radial-search can be found as the most appropriate for the deployment of hierarchical structures, management of enriched vocabulary as well as hierarchy and association relationships. Similarly, they can be found for the integration of search methods specifically oriented to thematic coverage from a subject or area of knowledge.

3. Use features: For this category, the interfaces tree, icicle and radial-search are found as the most suitable to facilitate navigation and implementation processes from a previously established knowledge representation scheme.

\section{Analysis of Libraries and Graphic Components}

The development of applications based on information visualization requires components which can facilitate their use, adaptation and support throughout a project lifetime. There is a long list of projects on the Internet that can actually smooth implementation of visualization techniques from a number of function libraries and APIs, Open-Sourcetype. Some of them consist of computational functions which use diagramming strategies such as the (SVG) Scalable Vector (based on forms). This type of diagramming offers superb capabilities to support graphics applications on most Internet browsers and the development of interactive applications without the need for specialized technologies.

Other similar technologies offer support capabilities to display code on any browser compatible with HTML5 features ("w3c.github.io,") combining canvas-type labels (based on pixels). This type of technology improves -to some extent- the user experience as it omits the installation of plugins or add-ons, since most browsers provide graphics natively, making hardware graphics acceleration easier [33]. Thus, for any vector graphics based on these technologies and depending on the activity performed, the developer should make greater efforts. Fig. 4 presents a valuation related to their performance, for the purpose of determining selection criteria according to the needs required for implementation. For example, the most promising graphic component to made data integration with repositories in visual search interfaces based on the experience of Oraganic.Edunet project [31] was D3js.

\section{Analysis of Search Criteria}

Finally, it is important the definition of search criteria based on metadata defined by digital resources to perform the implementation of visualization techniques. Search criteria based on metadata have been considered in several studies in the field of digital libraries [25]. For example, in the Europeana digital library [36], some search criteria are defined such as: subject, language, content provider, digital resource format (image, video, audio, etc.). In the MERLOT digital repository [37] the following are defined: knowledge area, title, author, type of digital resource, date of update and evaluation of the digital resource. Such strategies facilitate search processes of digital resources $[38,39$, $40,41]$.

A digital resource itself lacks features that may facilitate its access, use and subsequent reuse. Therefore, for a digital resource to be considered a learning object, it must have at least some of the following characteristics: i) educational and instructional design for
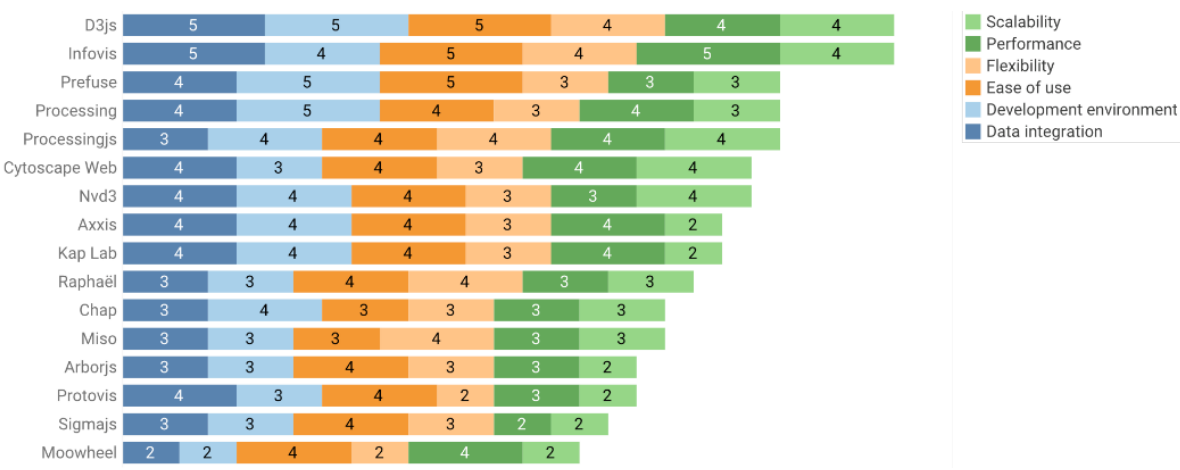

Fig. 4. Evaluation criteria for selection of visualization library. 
its creation [42]; ii) educational components for its use [43]; iii) a set of descriptions called metadata which help to achieve some degree of interoperability, accessibility and reusability between different systems $[44,45]$.

Metadata is data whose purpose is to provide a description of a learning object. In education, it facilitates the construction of a digital resource and determines the most suitable elements for specific learning needs. In the area of learning objects, the use of metadata is widely accepted as a means to increase its quality and reusability [46]. Therefore, metadata is used to describe learning objects in order to simplify information search and retrieval processes. In addition to this, metadata also becomes essential for obtaining appropriate search results and meeting the needs of users [22].

\section{ImPlications for DeVEloping INTERFACES BASED ON Visual SEARCH MethodS}

This section presents the challenges that information visualization faces for its implementation taking place in interfaces and as search methods on digital repositories which facilitate access to learning objects. These will be addressed by areas of interest in order to identify elements that allow reaching decisions when using this type of strategy.

A. Issues with Regard to Information Visualization in Digital Repositories

The effectiveness that information visualization may have in the field of digital repositories is something unquestionable. However, there are also a number of challenges concerning the application of solutions and / or the implementation of alternatives. That said, a list of challenges facing the implementation of such strategies on digital repositories is presented below. Firstly, development time and adaptation to visualization techniques taking into account the digital resources features within the repository: This implies doing the planning under certain frequency -and depending on the versions given in the development process- for the approach of usability testing which can facilitate interface growth and adaptation according to the most suitable access criteria for development.

Another challenge is learning curve acquired by the development team to perform the implementation of visualization techniques: It is important that the development group carrying out such solutions have basic knowledge for the management of structures and components that are part of the Vector Graphics Scalable (SVG) library functions, or Canvas APIs graphics (based on pixels) supported by HTML5 ("w3c. github.io,"), as the case may be. These are technologies which support the use of radial, hyperbolic, tree, in categories and other structures in general to manage on-screen graphics resources.

\section{B. Implications Associated with Knowledge Representation} Schemes

A knowledge representation scheme may have many implications within a classification process and management of digital resources. In addition to this and in the same manner, it can have a significant influence in search processes which are defined through the use of visualization techniques within a digital repository. In order to reduce this gap, it is important to identify the most frequent problems when using such representation strategies. The most relevant difficulties associated with the use are presented below: 1) Interface limitation to visualize and deploy the knowledge representation scheme based on thesauri [47];2) Confusion in the use of thesauri for search processes based on preferred and non-preferred terms [5]; 3) Terminological problems in search processes [3] is another aspect that is often attributed to the difficulties faced by both creators and users of a digital repository defined from a thesaurus; 4) Difficulties in having access to digital resources from the use of ontologies with multiple terminological definitions $[6,7] ; 5$ ) Errors associated with the meaning of taxonomy within an ontology $[2,4]$; 6) Errors related to the definition of an ontology, associated with inconsistency, and information redundancy [2].

All the aforementioned problems highlight the serious limitations of knowledge representation schemes, thesauri and ontologies, when providing access to digital resources, especially for end users who want to reuse such resources.

\section{Limitations Associated with Interface Design}

It is clear that information visualization cannot encompass a comprehensive and effective solution within a search process. However, its inclusion could facilitate access by implementing different techniques and search strategies. In this regard, the deployment of digital resources should be considered a part of the solutions that a creator of digital repositories needs to consider in order to facilitate basic elements of usability. To this end, it is important to make emphasis on the following principles from the point of view of the interface: a) The number of digital resources deployed in each consultation process must be shown clearly and in a visible area; b) It must have a paging mechanism to facilitate navigation as well as an instrument to set the number of actual pages that each query displays; c) The number of digital resources deployed per page must be clearly displayed considering the method of paging implemented; d) Each digital resource deployed by a list page should contain relevant information associated with the title, description, content provider, the digital resource connection with similar resources in the same area of knowledge and the best preview of digital resource (image, video); f) It is important to add the deployment of results by implementing mechanisms for evaluating digital resources, according to the profile that best suits the characteristics of the digital repository through evaluation: experts, registered users, professionals, students, etc.; g) It is necessary to classify the access to digital resources according to the characteristics of use of the digital resource (secondary education, higher education, ongoing education, vocational training, and university), the users' profiles (teachers, students and professionals), the formats of digital resource (image, video, $\mathrm{rtf}$ document, presentation, slides, etc.), and the digital resource language (English, Spanish, etc.).

Finally, two recent studies, which indicate how visualization techniques can be useful and effective for the access to collections of digital resources, are compared [8]. In addition to this, problems of usability associated with the use of search interfaces from factors related to the usefulness, ease of learning and knowledge of users on two academic repositories are presented (Organic.Edunet and VOA3R) [19]. These papers explore the fundamental reasons for problems related to usability at the light of the results of several usability studies carried out in the context of the European projects "Organic.Lingua" (www.organic-lingua.eu) and "VOA3R" (www.voa3r.eu), where two different digital repositories are being developed.

\section{Limitations Associated with the Quality of Metadata}

The creation of a metadata is an activity that is performed manually (one person) or automatically (a computer). This has generated a number of inconsistencies and limitations when managing them due to complex upgrade processes which are defined through hierarchical and semantic structures (knowledge representation scheme), from instruments such as: 1) The use of controlled vocabularies (e.g. Thesauruses), 2) The application of a domain of specific use (e.g. Ontologies), and 3) The application of a knowledge domain for free use (DBpedia).

Despite the fact that most repositories include knowledge classification systems (for example, ontologies, thesauri) to help manage the content by experts and creators of a digital repository, the 
lack of effective mechanisms restricts users to locate digital resources according to their search criteria. The success of the location of digital resources depends heavily on the quality with which the metadata is designed [48]. This factor is essential to obtain relevant search results from the use of search engines defined in a repository $[49,50]$. On the other hand, the quality of metadata is important for improving indexing strategies of learning objects stored in them $[16,40,51]$. Therefore, the omission of metadata negatively affects search results based on search criteria defined -for example- in a specific knowledge area.

The quality of the content is an indicator that allows evaluating digital resources. On this work scenario, there are several studies that refer to the design of methods to evaluate the quality of digital resources $[52,53,54]$ as well as the quality of existing content in digital resource collections $[51,52]$. Based on these methods, a series of assessment criteria are defined to carry out quality assessments of metadata on a collection of digital resources.

\section{CONCLUSIONS AND CONSIDERATIONS}

In general, and according to the analysis of this study, it is considered that the development of graphical interfaces associated with knowledge representation schemes indicate that repository creators should focus their efforts on: i) define levels of relationship and partnership between digital resources by using knowledge representation structures that support taxonomies (thesauri or ontologies); ii) work with user-friendly interfaces: (tree, radial or icicle) that support the use of navigation routes to identify the level of classification within the taxonomic structure, depending on the levels of hierarchy or depth provided by a repository; iii) link relevant metadata fields (fields for classifying resources) with the navigation structure to facilitate scanning processes by categories or knowledge areas as this offers users the possibility to have a more significant and effective alternative to a collection of digital resources; iv) have visual integration into the taxonomic structure and in the number of digital resources available in each category, in a proportional way. Since the thematic coverage is a factor that significantly improves access to a collection of digital resources, this becomes an important circumstance as long as the displayed results are visually appealing for the participant.

Undoubtedly, digital repositories must work hand in hand with strategies to facilitate the interoperability and reuse of digital resources based on semantic enrichment determined in their metadata. However, greater efforts should be exerted to facilitate access to large collections of digital resources by raising strategies for the management and maintenance of digital resources based on good design and development practices. Some of the most representative recommendations associated with the area of digital repositories are presented below: 1) Metadata quality management: Understood as those policy decisions which should be taken into consideration for the management and administration of the quality metadata so as to enhance the conditions of precision in its definition in order to improve relevant search results of digital resources. 2) Linking metadata fields associated by theme: It is important to define strategies by implementing metadata to facilitate the search for digital resources from a subject or knowledge area. This activity can be performed by LOM metadata defined as "classification" and "relation". This metadata provides a classification by areas or themes, something which could facilitate search results of digital resources according to a specific area of knowledge in order to simplify access to a collection of digital resources. 3) Knowledge representation scheme: Which means selecting a knowledge representation scheme with at least the following features: a) Taxonomic hierarchy: A basic definition of taxonomic hierarchy in order to facilitate the classification and use of the visualization technique. b) Hierarchical relationship and partnership: It is important to establish a partnership relationship or hierarchy within the structures of the established taxonomic structure to facilitate linking related terms (generic or specific) to the search process. c) Enriched vocabulary management: Providing expression capacity within the determined relationships from complementary terms that could provide search alternatives based on synonyms, non-preferred terms, etc. d) Defining search criteria: Depending on strategies of use given in the repository, it is essential to determine search criteria by defining metadata based on themes or knowledge areas to facilitate the exploration and interaction of users on a collection of digital resources. Similarly, it is crucial to integrate defined criteria given by the educational environment, such as profile users, language and types of digital resources, etc.

\section{REFERENCES}

[1] Gasevic, D.,Djuric, D., and Devedzic, V. "Model Driven Engineering and Ontology Development" (2nd ed.). book, Springer Publishing Company, Incorporated (2009).

[2] Gómez-Pérez, A. Facultad D. I. Evaluation of Taxonomic Knowledge in Ontologies and Knowledge Bases. "Banff Knowledge Acquisition for Knowledge-Based Systems, KAW'99”, 26, 6.1.1--6.1.18, (1999). Retrieved from http://sern.ucalgary.ca/KSI/KAW/KAW99

[3] Aitta, M., Kaleva, S., and Kortelainen, T. Heuristic evaluation applied to library web services. New Library World, 109(1/2), 25-45, (2008). JOUR. http://doi.org/10.1108/03074800810845985

[4] Noshairwan, W., Qadir, M. A. and Fahad, M. "Sufficient Knowledge Omission Error and Redundant Disjoint Relation in Ontology". In K. M. Wegrzyn-Wolska and P. S. Szczepaniak (Eds.), Advances in Intelligent Web Mastering: Proceedings of the 5th Atlantic Web Intelligence Conference -- AWIC'2007, Fontainbleau, France, June 25 -- 27, 2007 (pp. 260-265). inbook, Berlin, Heidelberg: Springer Berlin Heidelberg. http:// doi.org/10.1007/978-3-540-72575-6_42

[5] Shiri, A., and Revie, C. "Usability and user perceptions of a thesaurusenhanced search interface". Journal of Documentation, 61(5), (2005), 640-656. JOUR. http://doi.org/10.1108/00220410510625840

[6] Gašević, D., and Hatala, M. "Ontology mappings to improve learning resource search". British Journal of Educational Technology, 37(3), (2006), 375-389. article. http://doi.org/10.1111/j.1467-8535.2006.00611.x

[7] J. Z. Li, D. Gasevic, J. C. Nesbit and G. Richards, "Ontology Mappings Enable Interoperation of Knowledge Domain Taxonomies". 2nd LORNET Int. Annu. Conf. (2005).

[8] Gaona-García, P. A., Martín-Moncunill, D., Sánchez-Alonso, S., and García, A. F. "A usability study of taxonomy visualisation user interfaces in digital repositories". Online Information Review, 38(2), (2014), 284304. JOUR. http://doi.org/10.1108/OIR-03-2013-0051

[9] Ternier, S., Verbert, K., Parra, G., Vandeputte, B., Klerkx, J., Duval, E., \& Ochoa, X. "The ariadne infrastructure for managing and storing metadata". IEEE Internet Computing, 13(4). (2009).

[10] Sicilia, Miguel-Angel, et al. "Learning object analytics for collections, repositories \& federations." Proceedings of the Third International Conference on Learning Analytics and Knowledge. ACM, (2013).

[11] Sicilia, Miguel-Angel. "Metadata research: Making digital resources useful again?." Handbook of metadata, semantics and ontologies. (2014). $1-8$.

[12] Kumar, V., Nesbit, J., and Han, K. "Rating learning object quality with distributed Bayesian belief networks: the why and the how". In Fifth IEEE International Conference on Advanced Learning Technologies (ICALT’05) (2005), (pp. 685-687). In proceedings. http://doi.org/10.1109/ ICALT.2005.230074b06a286ea5152f1782b02f45b8f84e4edd15a @w3c. github.io. (n.d.). Retrieved from http://w3c.github.io/html/\#the-canvaselement

[13] Thelwall, Mike, and Kayvan Kousha. "Figshare: a universal repository for academic resource sharing?." Online Information Review 40.3 (2016): 333-346.

[14] Tsakonas, G., and Papatheodorou, C. "Exploring usefulness and usability in the evaluation of open access digital libraries". Information Processing \& Management, 44(3), (2008), 1234-1250. JOUR. http://doi.org/http:// dx.doi.org/10.1016/j.ipm.2007.07.008

[15] Carol Tenopir, D. Council on Library and Information Resources Use and 
Users of Electronic Library Resources: "An Overview and Analysis of Recent Research Studies", (2003).

[16] Nash, S. S. "Learning objects, learning object repositories, and learning theory: Preliminary best practices for online courses". Interdiscip. J. Knowl. Learn. Objects, vol. 1, (2005), pp. 217-228.

[17] Jeng, J. "Usability Assessment of Academic Digital Libraries: Effectiveness, Efficiency, Satisfaction, and Learnability”. Libri, 55(2-3), (2005), 96-121. http://doi.org/10.1515/LIBR.2005.96

[18] Hee Kim, H., and Ho Kim, Y. "Usability study of digital institutional repositories". The Electronic Library, 26(6), (2008), 863-881. http://doi. org/10.1108/02640470810921637

[19] Hartson, H. R., Shivakumar, P., and Pérez-Quiñones, M. A. Usability inspection of digital libraries: a case study. International Journal on Digital Libraries, 4(2), (2004), 108-123. JOUR. http://doi.org/10.1007/s00799003-0074-4

[20] Hitchcock, S., Woukeu, A., Brody, T., Carr, L., Hall, W., and Harnad, S. "Evaluating Citebase, an open access Web-based citation-ranked search and impact discovery service". (n.d.).

[21] Tsakonas, G., and Papatheodorou, C. "Exploring usefulness and usability in the evaluation of open access digital libraries". Information Processing \& Management, 44(3), (2008), 1234-1250. JOUR. http://doi.org/http:// dx.doi.org/10.1016/j.ipm.2007.07.008

[22] Cechinel, C., Sánchez-Alonso, S., and Sicilia, M. Á. (2009). "Empirical Analysis of Errors on Human-Generated Learning Objects Metadata. In F. Sartori, M. Á. Sicilia, and N. Manouselis" (Eds.), Metadata and Semantic Research: Third International Conference, MTSR 2009, Milan, Italy, October 1-2, 2009. Proceedings (pp. 60-70). inbook, Berlin, Heidelberg: Springer Berlin Heidelberg. http://doi.org/10.1007/978-3-642-04590-5_6

[23] Martin-Moncunill, David, et al. "Evaluating the practical applicability of thesaurus-based keyphrase extraction in the agricultural domain: Insights from the VOA3R project." Knowledge Organization 42.2 (2017): 76-89.

[24] Sánchez-Alonso, S., and Sicilia, M.-A. "Using an AGROVOC-based ontology for the description of learning resources on organic agriculture". In M.-A. Sicilia and M. D. Lytras (Eds.), Metadata and Semantics (2009), (pp. 481-492). inbook, Boston, MA: Springer US. http://doi. org/10.1007/978-0-387-77745-0_47

[25] Gaona-García, P. A., Stoitsis, G., Sánchez-Alonso, S., and Biniari, K. "An exploratory study of user perception in visual search interfaces based on SKOS". Knowledge Organization, 43(4), (2016), 217-238. JOUR. Retrieved from https://www.scopus.com/inward/record.uri?eid=2-s2.084981167175\&partnerID=40\&md5=7144f9aa3530ef59c4aa377546c7ab6b

[26] Gaona-García, P. A., Martin-Moncunill D., Montenegro-Marin, C. "Trends and challenges of visual search interfaces in digital libraries and repositories". The Electronic Library. 35.1 (2017): 69-98.

[27] Chrysafiadi, K., and Virvou, M. "A knowledge representation approach using fuzzy cognitive maps for better navigation support in an adaptive learning system". SpringerPlus, 2(1), 81. article. http://doi. org/10.1186/2193-1801-2-81

[28] Zeng, M. L., and Chan, L. M. Trends and issues in establishing interoperability among knowledge organization systems. J. Am. Soc. Inf. Sci. Technol., 55(5), (2004), 377-395. http://doi.org/10.1002/asi.10387

[29] Soler Monreal, C., and Gil Leiva, I. "Possibilities and limitations of thesauri in comparison with other systems of knowledge organization: folksonomies, taxonomies and ontologies". Revista Interamericana de Bibliotecología, 33(2), (n.d.), 361-377. Retrieved from http:// www.scielo.org.co/scielo.php?script=sci_arttext\&pid=S012009762010000200004\&lng=en\&nrm=iso\&tlng $=$ es

[30] Gaona-García, P. A., Sánchez-Alonso, S., and Montenegro Marín, C. E. "Visualization of information: A proposal to improve the search and access to digital resources in repositories". Ingenieria E Investigacion, 34(1), (2014), 83-89. JOUR. Retrieved from https://www.scopus.com/inward/ record.uri?eid $=2-\mathrm{s} 2.0-84902156291 \&$ partnerID $=40 \& \mathrm{md} 5=6 \mathrm{f} 9360 \mathrm{c} 1 \mathrm{c} 3 \mathrm{~b} 1$ $15235 \mathrm{be} 0 \mathrm{da} 38 \mathrm{e} 56 \mathrm{~b} 481 \mathrm{c}$

[31] Manouselis, Nikos, Kostas Kastrantas, Salvador Sanchez-Alonso, Jesus Cáceres, Hannes Ebner and Matthais Palmer. 2009. "Architecture of the Organic.Edunet Web Portal." International Journal of Web Portals 1, no. 1:71-91

[32] Šimek, Pavel, Jiri Vaněk, Vladimir Očenásek, Michal Stočes and Tereza Vogeltanzová. 2012. "Using Metadata Description for Agriculture and Aquaculture Papers." Agris On-Line Papers in Economics and Informatics 4:79-90.
[33] Boulos, M. N. K., Warren, J., Gong, J., and Yue, P. "Web GIS in practice VIII: HTML5 and the canvas element for interactive online mapping". International Journal of Health Geographics, 9(1), (2010), 14. article. http://doi.org/10.1186/1476-072X-9-14

[34] Ruecker, S., Radzikowska, M., and Sinclair, S. "Visual Interface Design for Digital Cultural Heritage". book, Brookfield, VT, USA: Ashgate Publishing Company. (2011).

[35] Doerr, Martin, et al. "The europeana data model (edm)." World Library and Information Congress: 76th IFLA general conference and assembly. 2010.

[36] Schell, George P., and Max Burns. "Merlot: a repository of e-learning objects for higher education." E-Service 1.2 (2002): 53-64.

[37] Chirita, P.-A., Gavriloaie, R., Ghita, S., Nejdl, W., and Paiu, R. "Activity Based Metadata for Semantic Desktop Search". (n.d.).

[38] Lytras, M. D., and Sicilia, M. Where is the Value in Metadata\&\#63; Int. J. Metadata Semant. Ontologies, 2(4), (2007), 235-241. article. http://doi. org/10.1504/IJMSO.2007.019442

[39] Ochoa, X., and Duval, E. "Quality Metrics for Learning Object Metadata". (n.d.).

[40] Park, J.-R. "Metadata Quality in Digital Repositories: A Survey of the Current State of the Art". Cataloging \& Classification Quarterly, 47(3-4), (2009), 213-228. JOUR. http://doi.org/10.1080/01639370902737240

[41] Wiley, David A. The instructional use of learning objects. Vol. 1. Bloomington, IN: Agency for instructional technology, 2002.

[42] Polsani, P. "Use and Abuse of Reusable Learning Objects". Journal of Digital Information, 3(4). (2006). article. Retrieved from https://journals. tdl.org/jodi/index.php/jodi/article/view/89

[43] Friesen, N. "Open Educational Resources: New Possibilities for Change and Sustainability". The International Review of Research in Open and Distributed Learning, 10(5). (2009). article. Retrieved from http://www. irrodl.org/index.php/irrodl/article/view/664

[44] Sanz, J., Dodero, J. M., and Sánchez-Alonso, S. "A Preliminary Analysis of Software Engineering Metrics-based Criteria for the Evaluation of Learning Objects Reusability". International Journal of Emerging Technologies in Learning (iJET), 4(0), (2009), 30-34. article. Retrieved from http://online-journals.org/index.php/i-jet/article/view/794

[45] Sicilia, M.-A., and Garcia, E. "On the Concepts of Usability and Reusability of Learning Objects". The International Review of Research in Open and Distributed Learning, 4(2). (2003). article. Retrieved from http://www.irrodl.org/index.php/irrodl/article/view/155

[46] Shiri, A. A., Revie, C., and Chowdhury, G. "Thesaurus-enhanced search interfaces". Journal of Information Science, 28(2), (2002), 111-122. http:// doi.org/10.1177/016555150202800203

[47] la Prieta, F., and Gil,A. B. "A Multi-agent System that Searches for Learning Objects in Heterogeneous Repositories". In Y. Demazeau, F. Dignum, J. M. Corchado, J. Bajo, R. Corchuelo, E. Corchado, ... A. Campbell (Eds.), Trends in Practical Applications of Agents and Multiagent Systems: 8th International Conference on Practical Applications of Agents and Multiagent Systems (2010) (pp. 355-362). inbook, Berlin, Heidelberg: Springer Berlin Heidelberg. http://doi.org/10.1007/978-3-642-124334_42

[48] Beltrán-Alfonso, R., Torres-Tautiva, A., Gaona-García, P.A.,MontenegroMarin, C.E. "Exploring the Relevance of Search Engines: An Overview of Google as a Case Study". International Journal of Interactive Multimedia and Artificial Intelligence, Vol. 4, n. 4 (2017). Retrieved from http://www. ijimai.org/journal/node/1519

[49] Muñoz-Arteaga, J., Calvillo-Moreno, E. A., Ochoa-Zezzatti, C. A., Santaolaya-Salgado, R., and Álvarez-Rodríguez, F. "Use of Agents to Realize a Federated Searching of Learning Objects. In Y. Demazeau, F. Dignum, J. M. Corchado, J. Bajo, R. Corchuelo, E. Corchado", ... A. Campbell (Eds.), Trends in Practical Applications of Agents and Multiagent Systems: 8th International Conference on Practical Applications of Agents and Multiagent Systems (2010) (pp. 1-8). inbook, Berlin, Heidelberg: Springer Berlin Heidelberg. http://doi.org/10.1007/978-3-642-12433-4_1

[50] Stuckenschmidt, H., and Van Harmelen, F. "Generating and managing metadata for Web-based information systems". (2004). http://doi. org/10.1016/j.knosys.2004.04.004

[51] Chuanjun, Suo. "On the Evaluation of the Quality of Digital Collections [J]." The Journal of The Library Science In China 4 (2004): 45-48.

[52] Downes, Stephen. "Models for sustainable open educational resources." Interdisciplinary Journal of E-Learning and Learning 
Objects 3.1 (2007): 29-44.

[53] Gonçalves, Marcos André, et al. “"'What is a good digital library?”-A quality model for digital libraries." Information processing \& management 43.5 (2007): 1416-1437.

[54] Sanz-Rodriguez, Javier, Juan Manuel Dodero, and Salvador SanchezAlonso. "Metrics-based evaluation of learning object reusability." Software Quality Journal 19.1 (2011): 121-140.

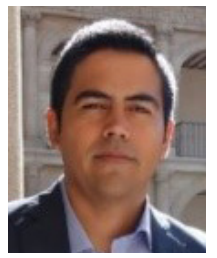

Paulo Alonso Gaona-García

Paulo Alonso Gaona García is titular professor at Engineering Faculty of Universidad Distrital Francisco José de Caldas, Bogotá - Colombia, and active member of GIIRA research group. He earned a Ph.D. in Information and Knowledge Engineering from the University of Alcalá in 2014. He is Master in Information Science and Communication from Universidad Distrital Francisco José de Caldas (Bogotá Colombia). His research interest includes data science, network and communications, e-learning, and visual analytics.

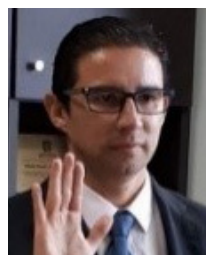

\section{Carlos Enrique Montenegro Marin}

Carlos Enrique Montenegro Marin is a Ph.D.in systems and computer services for internet from University of Oviedo, Asturias, Spain (2012). He has a Diploma of advanced studies 2008 of the Pontifical University of Salamanca. $\mathrm{He}$ is MSc. Science in Information and Communication Systems from the Universidad Distrital Francisco José de Caldas. He is a System engineer. His research interests include Object-Oriented technology, Language Processors, Modeling Software with, DSL and MDA.

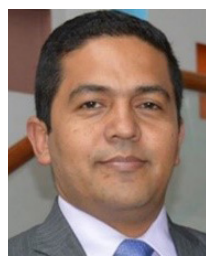

\section{Elvis Eduardo Gaona García}

Elvis Eduardo Gaona García is a Ph.D. in Engineering at Distrital University, Bogotá D.C. Colombia. He earned an M.Sc. in Information Science and Communications at Distrital University, Colombia. He is associated professor at Engineering Faculty of Distrital University. His research interests are network and communications, microgrids.

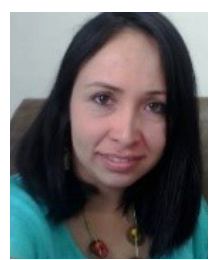

Adriana Gomez Acosta

Adriana Gomez Acosta, was born in Bogotá - Colombia. She is systems engineer, graduated from the San Mateo University Foundation. She has a master in Design and Management of technological projects of the University of La Rioja. Comes from a family traditionally dedicated to teaching; and precisely its line of professional training is oriented to university teaching and research in software development. She currently works as a research professor in the areas of Big Data and Business Intelligence, as well as advising projects of the Engineering Faculty of the San Mateo University Foundation.

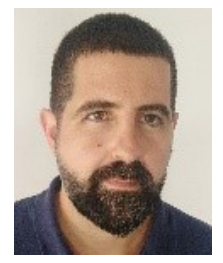

Yusef Hassan Montero

Yusef Hassan Montero has a PhD in Information Science from the University of Granada. Currently he works at UNIR (Universidad Internacional de la Rioja), where he directs the master's degree program in User Experience and teaches information visualization at the master's degree in Big Data and Visual Analytics. In addition, he collaborates with Scimago Lab in the design and development of scientific information interfaces. His research interests include Interaction Design, Human-Computer Interaction and Data Visualization. 